\title{
Mesoscopic comparison of interface tool/workpiece for simulation by FEM of EN AW 1350 bulk forming alloy
}

\author{
Fakhreddine Kherouf $^{1, a}$, Smail Boutabba ${ }^{2}$, Kamel Bey ${ }^{1}$, Ameur Chettah ${ }^{3}$ \\ AND J.-C. BOYER ${ }^{4}$ \\ 1 Laboratoire de Mécanique Industrielle, Université Badji Mokhtar, BP 12, 23000 Annaba, Algeria \\ 2 Laboratoire de Mécanique Appliquée des Nouveaux Matériaux, Université 8 mai 1945, BP 401, 24000 Guelma, Algeria \\ 3 BATir, Université Libre de Bruxelles, Avenue Roosevelt 87, Bruxelles 1050, Belgique \\ ${ }^{4}$ LaMCoS, INSA de Lyon, 20 avenue A. Einstein, 69621 Villeurbanne Cedex, France
}

Received 10 August 2013, Accepted 18 November 2014

\begin{abstract}
This paper presents an improved numerical simulation of bulk metal forming processes. It takes into the account the advanced formalism of large displacements and large deformations. Also, the interface workpiece formalism is considered. Metallographic studies are conducted to determine the evolution of the micro hardness as a function of annealing time and that to characterize accurately the plastic range of aluminum alloy for a range of plasticity $160 \%$. The obtained results of metallographic studies are used to simulate a upsetting under the friction law of the plastic wave. A numerical simulation by FEM of bulk forming alloy is carried out by replacing the real profile of the surface roughness by two triangular profiles, the first has the same height as the real profile and the second has the same area then by a trapezoidal profile of the same height. The obtained results are compared to Challen and Oxley results in order to validate the triangular profile used in the friction model of plastic wave.
\end{abstract}

Key words: Bulk forming / finite elements / roughness / plastic wave model / metallography

\section{Nomenclature}

\begin{tabular}{|ll|}
\hline$E$ & Young modulus $(\mathrm{MPa})$ \\
$\nu$ & Poisson ratio $(-)$ \\
$\rho$ & Mass density $\left(\mathrm{Kg} \cdot \mathrm{m}^{-3}\right)$ \\
$\alpha$ & Thermal expansion coefficient $\left(/ \mathrm{K}^{\circ}\right)$ \\
$K$ & Thermal conductivity $\left(\mathrm{W} \cdot \mathrm{m}^{-1} \cdot \mathrm{K}^{-1}\right)$ \\
$C_{p}$ & Specific heat $\left(\mathrm{J} \cdot \mathrm{Kg}^{-1} \cdot \mathrm{K}^{-1}\right)$ \\
$\sigma_{0}$ & Yield stress $(\mathrm{MPa})$ \\
\hline
\end{tabular}

\section{Introduction}

In the processes of bulk forming, friction plays an important role and sometimes is difficult to control. Many reported works propose several experimental tests to characterize friction [1]. In the field of plastic bulk forming, compression test of a ring is often used [2-5]. With this method, the friction can be estimated through the

\footnotetext{
a Corresponding author:

fakhreddinekherouf@gmail.com
}

change in the internal diameter of the deformed ring. In addition, the traditional test of compression of a cylinder can also be used to characterize friction during bulk forming operations $[6,7]$.

The most sophisticated manufacturing processes do not totally produce smooth surfaces. The characterization of the surface quality by the measurement of roughness plays a major part in the study of friction.

In this work a metallographic study is conducted along with the determination of micro-hardness evolution according to annealing time in order to characterize with precision the plastic range of EN AW 1350 aluminum alloy for a plasticity interval of $160 \%$.

The process of hot bulk forming is simulated with finite element method through ABAQUS calculation code using very fine mesh at contact interface. The main purpose of this simulation is to compare the microscopic level of stress sensitivity according to the geometry of roughness.

The paper is structured as follows: in section two, the theory of plastic wave friction is presented. The experimental procedure (hardness test, micrographic study, torsion test) is detailed in section three, the numerical simulation of the bulk forming processes is given in 
section four. The paper ends with concluding remarks and conclusion.

\section{Plastic wave friction modeling theory}

The bulk forming of material is obtained by applying a displacement field providing a predetermined geometry. Controlling the tool and billet contact conditions is the most important parameter for a successful bulk metal forming process. In fact, the friction at workpiece-tool interface does not only affect the surface state of the product but also its geometry and physical properties. Mastering the friction is often the key for an effective bulk forming material. Classical models of friction and contact resistance frequently used in the computing codes were proved to be less representative of physical reality in the field of forging operations. The classical friction tests for bulk forming processes are usually based on simple compression by a rigid punch. This test induces a heterogeneous strain hardening in the billets.

For axisymmetric geometry, the punches are machined by turning inserts with known circular geometry. The roughness parameters are identified by the roughness of few selected tracks to the punch. From these surveys, it is possible to deduct an equivalent roughness profile of triangular shape used in the formulation of the theory of plastic wave model.

A lot of microscopic models are developed in order to obtain a law of macroscopic friction. The plastic wave model, formulated with slip line theory and the upper bound, consider a plane strain field in a perfectly rigid plastic triangular asperity based on a $2 \mathrm{D}$ geometry and actual roughness, of circular shape, replaced by a triangular geometry of the same average height $R$ and the same wavelength $A R$. This model will allow to obtain a friction law at the interface according to normal contact stress, the roughness of the tool, the workpiece material yield stress and local constant friction coefficient $m_{0}$. In this model, the friction force opposes the sliding of the rough surface and the resulting growth in the plastic wave material of the workpiece. In the vicinity of the contact surface, the workpiece material flows like a viscous lubricant (the material is perfectly plastic) which gives rise to the frictional stress $\tau_{t}$.

$$
\begin{aligned}
\tau_{t}= & \frac{\sigma_{0}}{2 \sqrt{3} \cos \alpha} \\
& \times\left[\left\{1+2\left(\frac{\pi}{4}+\Phi-\eta\right)\right\} \sin \alpha+\cos (\alpha+2 \Phi)\right]
\end{aligned}
$$

with

$$
\begin{aligned}
\alpha+\Phi & =0.5 \arccos m_{0} \\
\eta & =\arcsin \left\{\left(1-m_{0}\right)^{-0.5} \sin \alpha\right\}
\end{aligned}
$$

where $\alpha$ is the tool asperity angle, $\Phi$ and $\eta$ are the characteristic angles of the plastic wave. According to experimental tests [8] the simulation is performed by taking an asperity angle $\alpha$ of $7^{\circ}$ with the corresponding values of
Table 1. Geometry of punch.

\begin{tabular}{ccc}
\hline Cone Angle & $R(\mu \mathrm{m})$ & $A R(\mu \mathrm{m})$ \\
\hline $7^{\circ}$ & 20.985 & 359.060 \\
\hline
\end{tabular}

roughness parameters defined by the international standard ISO 4287-1997.

\section{Experimental study}

\subsection{Treatments of re-crystallization annealing}

Taking into account materials breaking strength, aluminum and its alloys have a wide interval from $50 \mathrm{MPa}$ for refined aluminum at annealing state until a breaking strength of 65 to $750 \mathrm{MPa}$ for high-strength alloys strongly loaded by additional elements in the quenched state income of Al-Zn-Mg (7049A) type. Such a variety of mechanical properties is obtained from the alloy composition by conducting suitable thermal treatments. These treatments allow obtaining a reduction in the mechanical resistance and an increase in the aptitude for the plastic deformation (softening treatments) or in contrast an increase in the mechanical resistance (hardening treatments).

In addition to having an influence on the level of mechanical resistance, thermal treatments play an important role on other important properties such as the aptitude for anodic oxidation, electric conductivity or dimensional stability.

The annealing treatments of re-crystallization, which give new crystals [9], increase considerably the plasticity but decrease the elastic limit, the load rupture and hardness.

In this section the experimental tests are presented, cylindrical samples of $7 \mathrm{~mm}$ thickness and $20 \mathrm{~mm}$ diameter were cut from the heat-treated rods of the furnace at $320^{\circ} \mathrm{C}$. A minimum of three readings were taken on each sample in order to obtain reasonable statistics for the measured hardness values.

In this work the determination of hardness and a micrographic study were carried out on aluminum alloy samples. This study made possible the determination of grains size evolution and hardness according to annealing time. The purpose is to obtain a curve of large plasticity.

\subsection{Hardness test}

The material hardness characterizes its strength. A load is applied during a given time through a penetration on the surface of tested material. In this work an automatic micro-hardness meter with Vickers penetration is used as shown in Figure 2. 


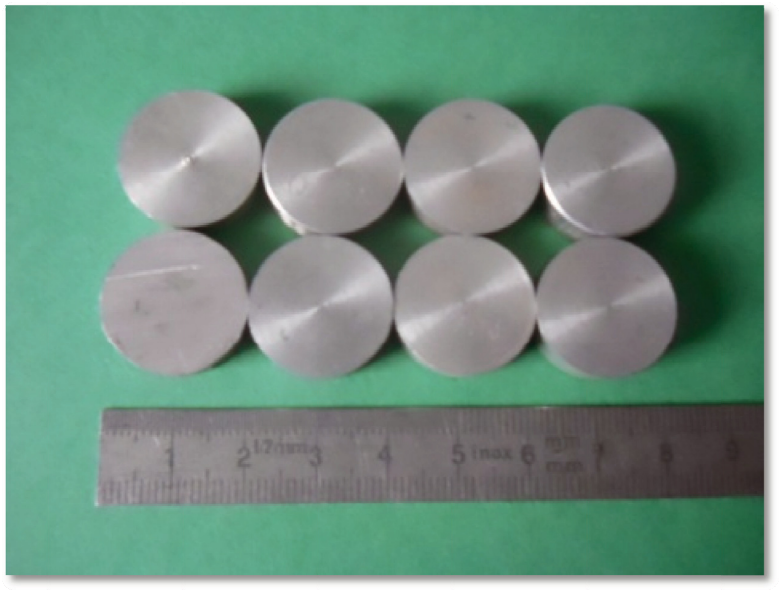

Fig. 1. Samples.



Fig. 2. Vickers pyramid hardness control machine.

Table 2. Hardness before thermal treatment.

\begin{tabular}{ccccc}
\hline & Test 1 & Test 2 & Test 3 & Average \\
\hline Vickers hardness & 40 & 41.3 & 41.7 & 41.3 \\
\hline
\end{tabular}

\subsubsection{Hardness before thermal treatment}

All hardness tests were carried out on the external faces of the samples previously polished as shown in Table 2.

\subsubsection{Hardness after thermal treatment}

The thermal treatment on samples was carried out with $320^{\circ} \mathrm{C}$ for a time up to $8 \mathrm{~h}$ as illustrated in Table 3 .

From the tests results, it is observed that sample hardness falls significantly during the first three hours of annealing, and then is stabilized at $22 \mathrm{HV}$ as shown in Figure 3 . The shape of our curve seems the good agreement with the results found in reference [10].
Table 3. Hardness after thermal treatment.

\begin{tabular}{ccccc}
\hline Annealing time $(\mathrm{h})$ & Test 1 & Test 2 & Test 3 & Average \\
\hline 1 h in furnace & 35 & 33.4 & 31.9 & 33.4 \\
$1 \mathrm{~h} 30$ & 28 & 26 & 27.9 & 27.3 \\
$2 \mathrm{~h}$ & 25.4 & 23.6 & 23.1 & 24 \\
$3 \mathrm{~h}$ & 23.1 & 22.5 & 22.3 & 22.6 \\
$4 \mathrm{~h}$ & 21.6 & 21.9 & 22 & 21.8 \\
$5 \mathrm{~h}$ & 23.8 & 19.3 & 21.2 & 21.4 \\
$8 \mathrm{~h}$ & 21.5 & 21.7 & 21.2 & 21.4 \\
\hline
\end{tabular}

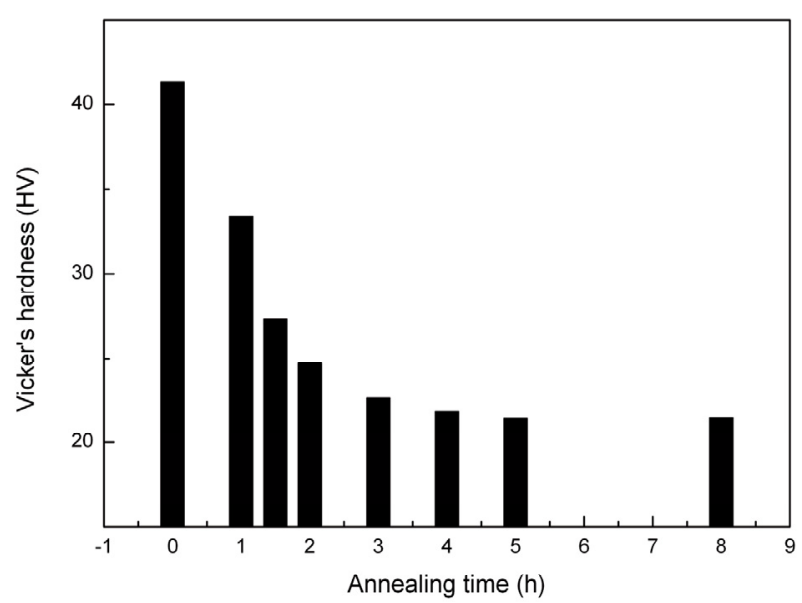

Fig. 3. Hardness evolution according to annealing time.

\subsection{Micrographic study}

Optical metallography enables to obtain information on elements constituting the microstructures such as cracks, textures, particles size and various phases.

Before micrographic control is carried out on the samples, a 4000 polishing with silicon abrasive carbide paper and finishing by alumina using a set diamonds paste of $1 \mu \mathrm{m}$ in order to obtain a bright surface free of stripes is required. To highlight grain boundaries, each specimen was immersed in an acid solution [11] Keller (distilled water $\mathrm{H}_{2} \mathrm{O}=95 \mathrm{ml}$, hydrofluoric acid $\mathrm{HF}=1 \mathrm{ml}$, nitric acid $\mathrm{NHO}_{3}=2.5 \mathrm{ml}$, hydrochloric acid $\mathrm{HCl}=1.5 \mathrm{ml}$ ) for 30 to $40 \mathrm{~s}$.

This is done in order to obtain a contrast between the various grains. The micrographic microscope is equipped with a numerical camera connected to a PC recording a large number of photographs of various microstructures with various zooms for each sample. Micrograph has a zoom of X200 (see Fig. 4).

The examination under the optical microscope allows observing the grain boundaries. For samples without thermal treatment, no grain boundary is visible even when the zoom is increased. For one hour of annealing, some unclear grains can be observed. A two hours annealing gives a slight difference, supposing a zoom of the grains. For three hours of annealing, the separation of the grains is more visible. For $4 \mathrm{~h}$ of annealing, no visible change compared to samples of three hours. After $5 \mathrm{~h}$ of annealing, it can be noted that samples microstructure has completely changed. For $8 \mathrm{~h}$ annealing, the grains size is similar to 


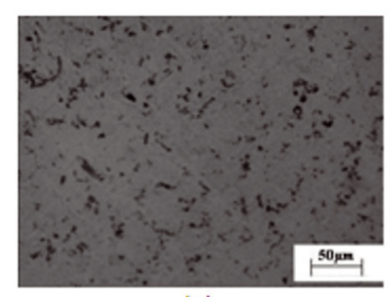

(a)

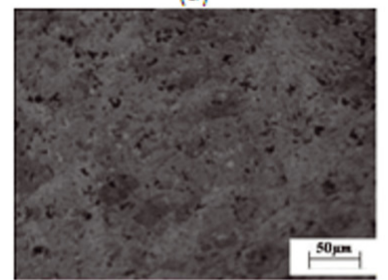

(d)

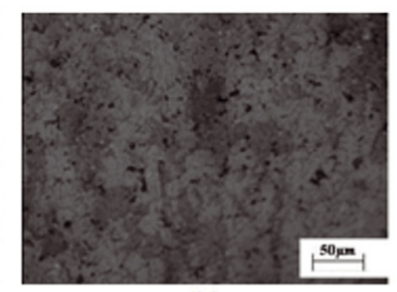

(b)

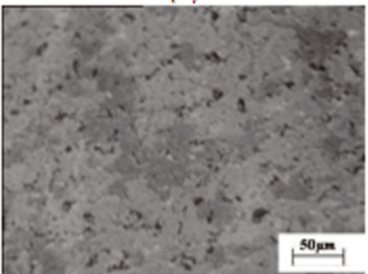

(e)

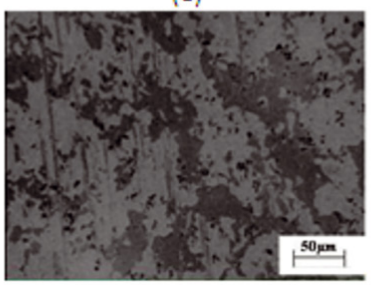

(g)

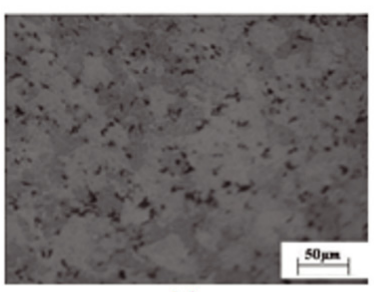

(c)

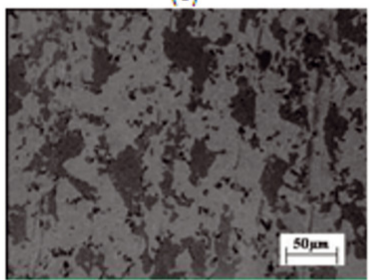

(f)

Fig. 4. Microstructure evolution: (a) without heat treatment, (b) after $1 \mathrm{~h}$ of heat treatment, (c) $2 \mathrm{~h}$, (d) $3 \mathrm{~h}$, (e) $4 \mathrm{~h}$, (f) $5 \mathrm{~h}$, (g) $8 \mathrm{~h}$.

that of $5 \mathrm{~h}$. In fact, for the development of a microstructure (grain growth) the heat treatment is one of the most important influencing parameters.

\section{Numerical simulation}

\subsection{Procedure}

The problem similarity allows considering calculation only for one half of the higher punch and a quarter of the billet.

Certain processes of bulk forming are carried out at hot to decrease the efforts to be implemented because of temperature conditions and the value of the yield stress $\sigma_{0}$ of deformed material [12]. The process is known as hot process when the temperature is higher than 0.5 times the absolute temperature of fusion $T_{f}$.

In this work, a simulation of bulk forming process of a cylindrical workpiece by a conical tool with calculation code using ABAQUS finite elements in thermal state is proposed. The forging of aluminum alloy billets preheated at a temperature of $400{ }^{\circ} \mathrm{C}$, near the melting point is carried out by a conical tool which takes into account the punch roughness.

\subsection{Roughness parameter}

The control of contact conditions between tool and workpiece is important and essential parameter of a successful materials bulk forming operation. Indeed, friction with the interfaces tool/workpiece does not condition only the surface quality of the product but also its geometry and its physical properties. Thus, the control of friction is often the key of the process effectiveness of materials bulk forming.

In fact, for axisymmetric geometries, the punches are machined by turning with inserts of known circular geometry. The parameters of roughness are identified by a profilometer for some chosen trajectories from the punch. From these statements, it is possible to deduce an equivalent profile of roughness used in the formulation from the theory of the plastic wave. The profile of real roughness is replaced by a triangular profile of the same surface, a triangular profile of the same height and then by a trapezoidal profile of the same height as illustrated in Figure 5.

The roughness parameters are in conformity with the standard ISO 4287 (1997). In this work, the average height $R$ and the average width $A R$ of the evaluated profile are taken in account [8].

\subsection{Material}

The current tendency is the substitution of steel and cast iron by aluminum, taking into account the rise in the fuel costs and the problems of environment. This is also justified by its lightness and its corrosion resistance in the aeronautical and car industries to produce light structural parts such as the fuselages and the aircraft wings or vehicles parts. Therefore, it is necessary that the ratio of aluminum alloy resistance to its weight will be more 




(a)

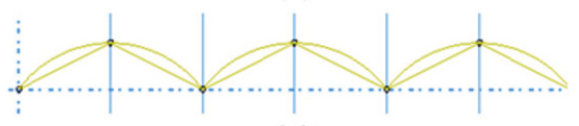

(c)

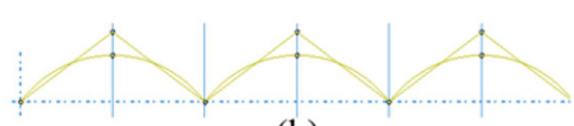

(b)

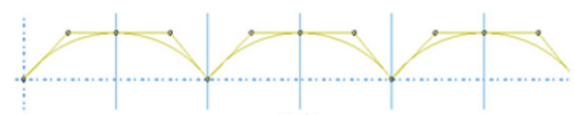

(d)

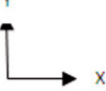

Fig. 5. Profile of roughness: (a) circular, (b) triangular of the same surface, (c) triangular of the same height, (d) trapezoidal.

Table 4. Chemical composition of EN AW 1350 Aluminum Alloy.

\begin{tabular}{ccccccccc}
\hline $\mathrm{Fe}$ & $\mathrm{Si}$ & $\mathrm{Cu}$ & $\mathrm{Zn}$ & $\mathrm{Cr}$ & $\mathrm{Ti}$ & $\mathrm{Mg}$ & $\mathrm{Mn}$ & $\mathrm{Al}$ \\
\hline 0.19 & 0.11 & 0.023 & 0.038 & 0.010 & 0.018 & 0.021 & 0.09 & $\mathrm{Bal}$ \\
\hline
\end{tabular}

Table 5. Thermal and mechanical properties of the punch.

\begin{tabular}{cc}
\hline Properties & Values \\
\hline Young modulus $E$ & $210000 \mathrm{MPa}$ \\
Poisson ratio $\nu$ & 0.28 \\
Mass density $\rho$ & $7700 \mathrm{Kg} \cdot \mathrm{m}^{-3}$ \\
Thermal expansion coefficient $\alpha$ & $1.3 \mathrm{e}-005 / \mathrm{K}^{\circ}$ \\
Thermal conductivity $K$ & $50 \mathrm{~W} / \mathrm{m} /{ }^{\circ} \mathrm{K}$ \\
Specific heat $C_{p}$ & $460 \mathrm{~J} / \mathrm{kg} /{ }^{\circ} \mathrm{K}$ \\
\hline
\end{tabular}

Table 6. Thermal and mechanical properties of the billet.

\begin{tabular}{cc}
\hline Properties & Values \\
\hline Young modulus $E$ & $69000 \mathrm{MPa}$ \\
Poisson ratio $\nu$ & 0.33 \\
Mass density $\rho$ & $2700 \mathrm{Kg} \cdot \mathrm{m}^{-3}$ \\
Thermal expansion coefficient & $2.4 \mathrm{e}-005 / \mathrm{K}^{\circ}$ \\
Thermal conductivity $K$ & $230 \mathrm{~W} / \mathrm{m} /{ }^{\circ} \mathrm{K}$ \\
Specific heat $C_{p}$ & $1000 \mathrm{~J} / \mathrm{kg} /{ }^{\circ} \mathrm{K}$ \\
\hline
\end{tabular}

important than that of the replaced alloy. Moreover the use of new materials imposes additional investments on equipment and labor formation which has to be taken in consideration.

The numerical modeling of bulk forming processes (forging, stamping,...) requires materials mechanical characteristics determination in both elastic area and great plastic deformations (deformation from $100 \%$ to $300 \%)$.

The precise knowledge of these mechanical properties is usually required in various technological applications such as aeronautics $[13,14]$ car industry $[15,16]$, marine $[17,18]$ and fields of mechanical manufacture [19].

For the alloy EN AW 1350 aluminum sample, chemical composition is given in Table 4 .

For forging process modeling, the punch material is supposed to be rigid on alloy steel with a combination of mechanical and thermal properties (see Tab. 5).

The properties of workpiece material in aluminum alloy are given in Table 6 .



Fig. 6. Stress-strain curve of the billet material.

In this work, a torsion test is carried out for which an important flow zone is obtained. Aluminum alloy specimens, having a length of $115 \mathrm{~mm}$ and diameter of $\varnothing 6 \mathrm{~mm}$, underwent a preliminary annealing of $8 \mathrm{~h}$ at $320^{\circ} \mathrm{C}$. The stress-strain curve was noticed up to $160 \%$ as illustrated in Figure 6.

\subsection{Mesh}

The ABAQUS software is used for the determination of the stress distribution in the contact zone. The mesh of the punch and the workpiece is conducted with CAX4R element with reduced integration and hourglass control [20]. The element is a bilinear membrane axisymmetric element with flat constraint having 4 nodes; each node has 3 degrees of freedom namely two translations (one is radial and the other following the generator) and a temperature. A mesh refinement is applied at the interface tool/workpiece (14 elements in front of each tool asperity). This simulation has led to 10735 elements for workpiece mesh and 523 for the tool (see Fig. 7).

\subsection{Boundary conditions}

The workpieces are cylindrical with an initial diameter of $60 \mathrm{~mm}$ and an initial height of $80 \mathrm{~mm}$, the higher 


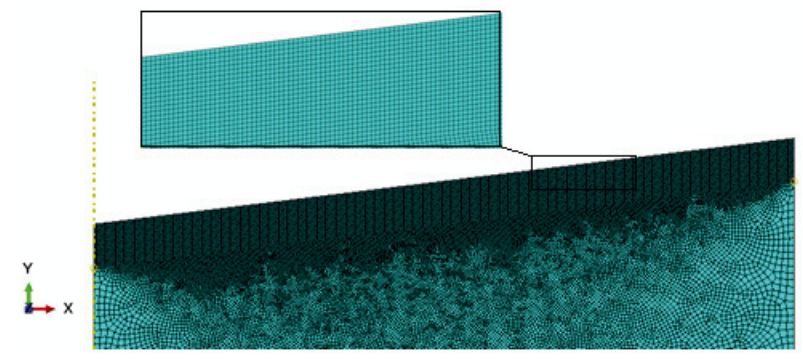

Fig. 7. Workpiece mesh.

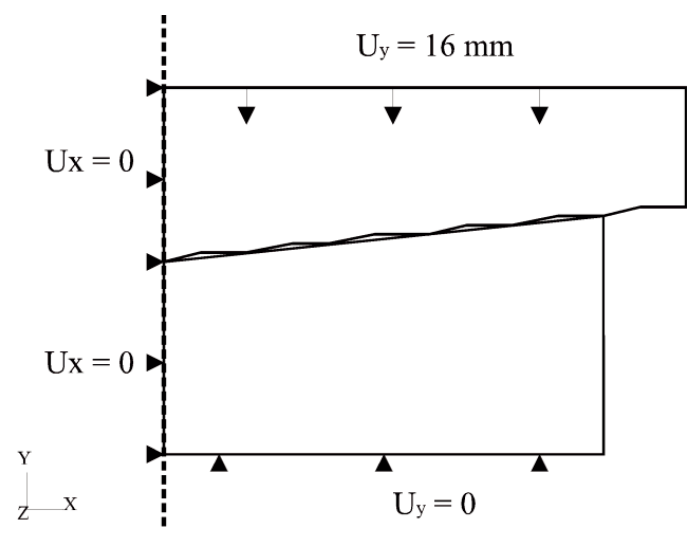

Fig. 8. Boundary conditions.

base is conical with an inclination angle of $7^{\circ}$. The interface is modeled with the assumption of a zero friction and the mesh is made very fine around the contact zone. The punch decreases at a constant speed with a length of $16 \mathrm{~mm}$ subdivided on 165 different positions. As for the boundary conditions Figure 8, transverse displacement is blocked in the base level as well as radial displacement on the symmetry axis. The problem symmetries allow considering only one half of one punch and one quarter of the billet.

\section{Results and discussions}

The problem of contact between a rigid tool and a deformable billet to improve the conditions of bulk forming by plastic deformation is a current problem, which is the subject of many researches by simulation and experimental methods to characterize the friction parameters to the interface [21-24]. The modeling of the contact and friction to the interface remains until now rather difficult to characterize taking into account the complex dynamic state between the asperities of the tool and the stress raised in the workpiece.

The analysis of stress distribution Von Mises at the interface level allows considering the roughness form of most adapted to real roughness.

On Figure 9, $\mathrm{H}$ curve represents a stress for triangular roughness of the same height as a real roughness, Tra represents the roughness of trapezoidal form, whereas, C represents the circular roughness and $\mathrm{S}$ represents triangular roughness of the same surface.

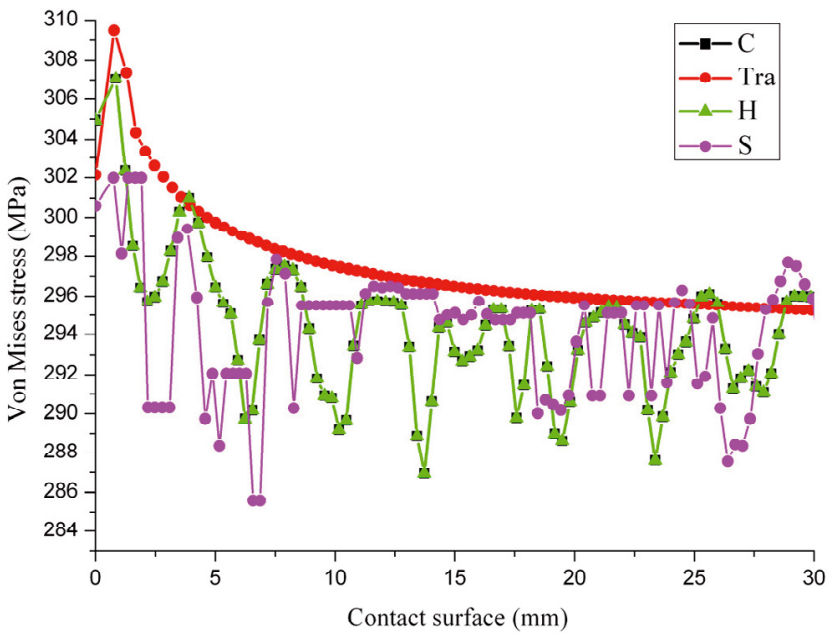

Fig. 9. Von Mises stress distribution in workpiece surface along the radial direction.

The diagram represents the value of the stress according to the distance in $\mathrm{mm}$ compared to the axis of symmetry. It is noted that the value of the stress at the level of the axis of symmetry of the workpiece is more important (309 MPa) for the trapezoidal asperity than for the circular and triangular asperity of the same height (306 MPa) while for the triangular asperity of the same surface the value is lower (301 $\mathrm{MPa})$.

At the external surface of the workpiece it can be observed, a reduction in the stress Von Mises for three profiles, $296 \mathrm{MPa}$. The trapezoidal profile gives a decreasing monotonous distribution of the stress equivalent Von Mises from $309 \mathrm{MPa}$ to $296 \mathrm{MPa}$, on the other hand the triangular profile of the same height gives results identical to those of the real profile. These studies highlight that there is no influence of the geometry of the trapezoidal roughness (Tra), although it appears the stress peaks very marked at the tops of the asperities (von Mises's higher). The results presented in this figure show that the asperities are more prominent, more stress produced is important because roughness inhibits plastic flow of the billet.

These results confirm that the profile best adapted for the theory of the plastic wave is a triangular profile of the same height as indicated in Challen and Oxley [25] and other reported works [26].

\section{Conclusion}

In this paper, an experimental study carried out for the determination of the micro hardness of EN AW 1350 aluminum alloy and a micrographic analysis of various alloy thermal treatments in order to choose the treatment best adapted to obtain a characteristic presenting a large interval of the plasticity range. Torsion tests on EN AW 1350 aluminum alloy specimens were conducted to characterize material in the plastic range. The curves obtained are introduced into the calculation programmed to simulate the behavior of the interface tool/workpiece 
in forging operation. A numerical simulation of plastic flow inside the asperities of a rough surface in the upsetting of an axisymmetric billet in EN AW 1350 proves that the equivalent stress distribution at the surface of the workpiece is very sensitive to the adopted geometry of the punch profile.

Acknowledgements. The authors wish to thank Prof. K. Necib, Mr. May and Mr. Hamouche for their assistance in the experimental part.

\section{References}

[1] Q. Zhang, M. Arentoft, S. Bruschi, L. Dubar, E. Felder, Measurement of friction in a cold extrusion operation: Study by numerical simulation of four friction tests, Int. J. Mater. Form. Suppl 1 (2008) 1267-1270

[2] S.B. Petersen, P.A.F. Martins, N. Bay, Friction in bulk metal forming: a general friction model vs. the law of constant friction, J. Mater. Process. Technol. 66 (1997) 186-194

[3] M.S. Joun, H.G. Moon, I.S. Choi, M.C. Lee, B.Y. Jun, Effects of the friction law on metal forming processes, Tribol. Int. 42 (2009) 311-319

[4] S. Hasan, R. Jahan, On the measurement of friction coefficient utilizing the ring compression test, Tribol. Int. 32 (1999) 327-335

[5] A.T. Male, M.G. Cockcroft, A method for the determination of the coefficient of friction of metals under condition of bulk plastic deformation, J. Inst. Metals 93 (1964) $38-46$

[6] R. Ebrahimi, A. Najafizadeh, A new method for evaluation of friction in bulk metal forming, J. Mater. Process. Technol. 152 (2004) 136-143

[7] X. Tan, Comparisons of friction models in bulk metal forming, Tribol. Int. 35 (2002) 385-393

[8] E. Vidal-Sallé, S. Boutabba, Y. Cui, J.C. Boyer, An improved "plastic wave" friction model for rough contact in axisymmetric modelling of bulk forming processes, Int. J. Mater. Form 1 (2008) 1263-1266

[9] M. Schikorra, L. Donati, L. Tomesani, A.E. Tekkaya, Microstructure analyses of aluminum extrusion: grain size distribution in AA6060, AA6082 and AA7075 alloys, J. Mech. Sci. Technol. 21 (2007) 1445-1451

[10] R. Develay, Traitements thermiques des alliages d'aluminium, Techniques de l'ingénieur, M 1290 (2000) 13

[11] A.M. Habraken, C. Bouffioux, M. Carton, J.L. Beckers, Study of a 2024 aluminium rod produced by rotary forging, J. Mater. Process. Technol. 184 (2007) 19-26
[12] E. Felder, Procédés de mise en forme - Introduction, Techniques de l'Ingénieur, M 3000 (2000) 4

[13] D. Karagiozova, R. Mines, Impact of aircraft rubber tyre fragments on aluminium alloy plates: II-numerical simulation using LS-DYNA, Int. J. Impact Eng. 34 (2007) 647-667

[14] D. Varas, R. Zaera, J. López-Puente, Numerical modelling of the hydrodynamic ram phenomenon, Int. J. Impact Eng. 36 (2009) 363-374

[15] A. Rusinek, R. Zaera, P. Forquin, J.R. Klepaczko, Effect of plastic deformation and boundary conditions combined with elastic wave propagation on the collapse site of a crash box, Thin-Walled Structures 46 (2008) 1143-1163

[16] Z. Kazanci, K. Bathe, Crushing and crashing of tubes with implicit time integration, Int. J. Impact Eng. 42 (2012) 80-88

[17] Z. Zong, Y. Zhao, H. Li, A numerical study of whole ship structural damage resulting from close-in underwater explosion shock, Marine Structures 31 (2013) 24-43

[18] S. Ehlers, The influence of the material relation on the accuracy of collision simulations, Marine Structures 23 (2010) 462-474

[19] W. Hui, L. Ying-bing, P. Friedman, C. Ming-he, G. Lin, Warm forming behavior of high strength aluminum alloy AA7075, Trans. Nonferrous Met. Soc. China 22 (2012) $1-7$

[20] H. Marouani, M. Rachik, E. Hug, Experimental investigations and FEM simulations of parameters influencing the Fe-(wt.3\%) Si shearing process, Mech. Industry 13 (2012) 271-278

[21] T. Skare, F. Krantz, Wear and frictional behaviour of high strength steel in stamping monitored by acoustic emission technique, Wear 255 (2003) 1471-1479

[22] K. Louaisil, M. Dubar, R. Deltombe, A. Dubois, L. Dubar, Analysis of interface temperature, forward slip and lubricant influence on friction and wear in cold rolling, Wear 266 (2009) 119-128

[23] D.K. Leu, Modeling of surface roughness effect on dry contact friction in metal forming, Int. J. Adv. Manuf. Technol. 57 (2011) 575-584

[24] S. Sah, R.X. Gao, An experimental study of contact pressure distribution in panel stamping operations, Int. J. Adv. Manuf. Technol. 55 (2011) 121-132

[25] J.M. Challen, P.L.B. Oxley, An expiation of the different regimes of friction and wear using asperity deformation models, Wear 53 (1979) 229-243

[26] E. Vidal-Salle, A. Dubois, M. Dubar, L. Dubar, J.C. Boyer, Experimental identification and validation of the plastic wave approach in hot forging of steels, Wear 286287 (2012) 35-44 